\title{
Two eminently treatable genetic metabolic myopathies
}

\author{
Woon-Chee Yee \\ Department of Clinical Research, Singapore General Hospital, Singapore
}

\begin{abstract}
Treatment of the genetic metabolic myopathies remains generally unsatisfactory with the exception of a select few. Multiple Acyl Co-A Dehydrogenase Deficiency (Glutaric Aciduria type II), in particular, has been shown to respond well to riboflavin supplementation. Recently, studies have also confirmed the effectiveness of recombinant enzyme replacement therapy for Acid Maltase Deficiency (Pompe's Disease). Accurate and early diagnosis of these diseases is vital to prevent serious complications and impaired recovery following delayed treatment.
\end{abstract}

Key words: Acid maltase deficiency, enzyme replacement therapy, glutaric aciduria Type II, human recombinant $\alpha$-glucosidase, multiple Co-A dehydrogenase deficiency, Pompe disease, riboflavin

\section{Introduction}

The genetically inherited metabolic myopathies encompass a large group of diseases associated with diverse inborn errors of metabolism, in particular muscle energy production, and including disorders of glycogen, lipid and mitochondrial metabolism. Despite major advances in understanding their molecular mechanisms and the identification of causative genes, treatment of these diseases remains inadequate or lacking. Nevertheless, a very small number of these diseases are amenable to treatment that may substantially reverse disease manifestations. Timely and accurate diagnosis of these diseases is, therefore, vitally important. However, owing to their relative rarity and wide range of presentations, these treatable diseases are often missed or diagnosed late. This review will focus on two specific metabolic myopathies for which appropriate therapy can significantly ameliorate or effectively cure the disease.

\section{Multiple Acyl CoA Dehydrogenase Deficiency (Glutaric Aciduria II)}

To the neurologist or neuromuscular specialist, multiple acyl co-A dehydrogenase deficiency (MADD) will likely be encountered in its late onset form presenting as a lipid storage myopathy. The pediatrician may encounter the distinct manifestations of severe neonatal MADD with hypoglycemic encephalopathy, hypotonia, organomegaly and sweaty feet odor, as well as the above myopathic form in childhood or adolescence. While no data on incidence is available, the disorder is probably not exceptionally rare.

\section{Molecular and metabolic pathophysiology}

MADD is an autosomal recessive disorder that results from a defect of electron transfer from the primary flavoprotein dehydrogenases to coenzyme Q10 in the mitochondrial electron transport chain. ${ }^{[1-3]}$ The disorder is linked to mutations in one of three genes coding for electron transfer flavoprotein (i.e. ETF $\alpha$ and $\beta$ subunits) and its electron acceptor, ETFubiquinone oxidoreductase (ETF-QO), which together are responsible for this electron transfer process. ${ }^{[3-7]}$ The genes are respectively denoted as ETF-A, ETF-B and ETF-DH. The generalized defect of dehydrogenase function that results leads to impairment of fatty acid, amino acid and choline metabolism, although the biochemical and histological manifestations are largely related to disordered fatty acid $\beta$-oxidation associated with four chain-length specific dehydrogenases. MADD is the same disorder as Glutaric Aciduria II (GAII) and Ethylmalonic-Adipic Aciduria, which were terms used to denote cases identified by the characteristic urinary organic acid metabolites associated with the disorder. $^{[1,8,9]}$

\section{Clinical features}

Three clinical phenotypes have been characterized for MADD. ${ }^{[3,10-13]}$ Two forms of the disease present in the neonatal period and share several common features, i.e. hypoglycemic encephalopathy associated with hypotonia, metabolic acidosis, organomegaly and sweaty feet odor. The more severe Type I is distinguished from Type II by additional features of congenital anomalies and early, inevitable death. Patients with the relatively 
milder or late onset form (Type III) typically present with a lipid storage myopathy associated with slowly progressive proximal weakness, reduced effort tolerance and muscle pain. The course in these patients may be punctuated by acute episodes of exacerbation with increased weakness, lethargy, vomiting, hypoglycemia and metabolic acidosis, often associated with physical stress. There may be hepatomegaly. However, the disease course and age of presentation in Type III can vary considerably, with onset ranging from early childhood to adult life, and the identification of asymptomatic as well as severe cases with respiratory failure.

Recently, another phenotype variation was identified as associated with MADD. Patients from five families, originally diagnosed to have an isolated myopathic form of coenzyme Q10 deficiency based on biochemical analysis of muscle respiratory chain complexes and coenzyme Q10, were found by tandem mass spectrometry (see below) to have MADD. ${ }^{[14]}$ Their clinical presentation was, in fact, consistent with the Type III form of MADD. All these patients were found to have autosomal recessive mutations in ETF-DH.

\section{Differential diagnosis}

While the infantile forms are distinctive, the differential diagnosis will include other diseases with Reye's syndrome-like presentation in infancy. In Type III MADD, especially in juveniles and adults, the apparent presentation as an acquired myopathy may entail a very broad differential diagnosis. Misdiagnosis as polymyositis has been reported. ${ }^{[15]}$ The association of the myopathy with acute exacerbations, especially if triggered by physical stress and accompanied by vomiting and metabolic changes, should raise suspicion of MADD, although such exacerbations may also be seen in other mitochondrial disorders.

\section{Diagnostic tests}

In patients presenting primarily as a myopathy, the muscle biopsy will likely provide the first suggestion of a possible diagnosis of MADD. Confirmation of the diagnosis, however, will require relatively complicated tests that are performed by special laboratories, namely urinary organic acid analysis by gas chromatography/ mass spectrometry or acylcarnitine profiling by tandem mass spectrometry. Molecular gene testing of the genes linked to the disease can also confirm the disease as well as identify the specific gene involved.

\section{Muscle biopsy}

The muscle biopsy in MADD shows typical features of a lipid storage myopathy, with multiple small vacuolar changes in muscle fibers that are revealed on lipid stains to be associated with increased droplet accumulations of lipid. Mild changes of mitochondrial dysfunction, e.g. a few "ragged red fibers" or cytochrome oxidase negative fibers, may also be present.

\section{Urinary organic acids}

MADD/GAII is characterized by elevated amounts of glutarate, ethylmalonate, isovalerate, $\alpha$-methylbutyrate, isobutyrate, aliphatic dicarboxylic acids and their derivatives. ${ }^{[16]} \mathrm{MADD} /$ Ethylmalonic-adipic aciduria is associated with elevated amounts of ethylmalonate, adipate and hexanoylglycine. ${ }^{[17]}$ The identification of these patterns by gas chromatography/mass spectrometry is diagnostic of MADD. However, unlike the neonatal forms which show marked elevation of urinary organic acids, in the milder Type III form, the organic aciduria may only be evident during the episodes of exacerbation.

\section{Acylcarnitine profiling by tandem mass spectrometry}

If tandem mass spectrometry (MS/MS) screening of serum or dried blood spot samples is available, the identification of increased concentrations of short, medium and long chain acylcarnitines (C4-C12) is characteristic of MADD. ${ }^{[18]}$ This test has proven useful in identifying MADD cases in countries where MS/MS has been adopted for neonatal screening using dried blood spots.

\section{Molecular gene testing}

All three MADD clinical phenotypes have been associated with each of the three genes linked to MADD. This suggests that mutational analysis of all three genes, i.e. ETF-A, ETF-B and ETF-DH, may be required to identify the specific genetic mutations in the individual patient. However, in view of the relatively frequent reports of late onset cases with ETF-DH mutations, ${ }^{[14]}$ it may be appropriate to start with mutational analysis of ETF-DH in late onset Type III MADD.

\section{Free carnitine and free fatty acid levels}

Free carnitine levels in the blood may be decreased in MADD, although this also occurs in other diseases with secondary carnitine deficiency and in primary carnitine deficiency. In the Type III form, carnitine levels may only be reduced during episodes of exacerbation. Likewise, free fatty acid levels in plasma may be elevated in MADD. Though not confirmatory for the diagnosis of MADD, both tests, if available, may help support the diagnosis.

\section{Treatment}

MADD has consistently been reported to respond dramatically to oral riboflavin supplementation, with rapid remission of symptoms and signs. ${ }^{[4,5,13,14,19,20]}$ Full recovery towards normality is seen in milder cases, and although recovery was said to be partial in severe neonatal cases, early therapy may possibly improve 
results. In this sense, MADD is an eminently treatable disease. The optimal riboflavin dose is unknown and may likely vary with disease severity, although doses up to $150 \mathrm{mg}$ daily have been employed. Interestingly, among the patients with coenzyme Q10 deficient myopathy associated with ETF-DH gene mutations, although all showed improvement with coenzyme Q10 supplementation, two responded well to riboflavin alone without coenzyme Q10. However, in one patient, the combination of riboflavin and coenzyme Q10 was better than riboflavin alone. Hence, at least for those cases of MADD associated with ETF-DH mutations, it has been suggested that long-term therapy should include coenzyme Q10 in addition to riboflavin. ${ }^{[14]}$

General recommendations for the management of MADD include dietary management with low lipid, low protein, high carbohydrate intake, and the avoidance of physical stress. Because of the finding of low carnitine levels, supplementation with carnitine has also been suggested. ${ }^{[10]}$ However, the efficacy of carnitine is unclear, as aggravation of MADD symptoms has also been reported following addition of carnitine. ${ }^{[21]}$

\section{Acid Maltase Deficiency (Glycogen Storage Disease Type II, Pompe's Disease)}

Acid maltase deficiency (AMD), also known as glycogen storage disease Type II and Pompe's disease, ${ }^{[22,23]}$ was first linked to an inherited deficiency of a lysosomal enzyme in 1963. ${ }^{[24]}$ However, although attempts to treat the disease with enzyme replacement began not long after, they were unsuccessful until very recently. With the approval by US and European drug administrations in 2006 of a recombinant enzyme as therapy for AMD, the possibility to effectively treat this disease has now emerged.

\section{Molecular and metabolic pathophysiology}

AMD is caused by deficiency of the lysosomal enzyme acid $\alpha$-glucosidase (GAA) as a result of autosomal recessive mutations in the GAA gene located on Chromosome 17. ${ }^{[25,26]}$ About 150 mutations have been associated with the disease, although common mutations have been reported in some communities, e.g. the IVS1-13T $>$ G splice site mutation in $70 \%$ of adult Caucasian patients ${ }^{[27]}$ and the Asp645Glu mutation in most Pompe infants in Taiwan. ${ }^{[28]}$ GAA acts to break down glycogen to glucose within lysosomes. Loss of functional GAA leads to the accumulation of glycogen within the lysosomes and in sarcoplasm with rupture of the lysosomal membrane. Glycogen accumulates in all tissues, most prominently in skeletal and cardiac muscle, where it likely impairs contractile function and reduces muscle mass via impaired regenerative capacity and increased apoptosis.

\section{Clinical features}

The incidence of AMD shows ethnic and geographical variation. In the Western world, the combined estimated frequency of AMD is 1:40,000. ${ }^{[29,30]}$ Pompe's disease of infants appears relatively more common in Taiwan and Southern China and among African-Americans, while later onset AMD appears relatively more common in the Netherlands.

The clinical phenotype of AMD exists as a continuous spectrum from severe, rapidly progressive early onset forms to more slowly progressive, less severe late onset forms. ${ }^{[22,31]}$ Disease severity seems to correlate with the level of residual GAA activity. In clinical practice and for teaching purposes, it remains useful to categorize AMD according to clinical subtype.

\section{Infantile acid maltase deficiency (classic Pompe's disease)}

The term Pompe's disease was originally applied to the severe infantile form, although there is a trend to use it for the entire spectrum of AMD. Symptoms typically present within two months after birth, initially as poor motor development and failure to thrive. ${ }^{[32]}$ These infants develop feeding difficulties, profound muscle weakness and floppiness, and respiratory difficulties often complicated by pneumonia. Almost all patients develop cardiomyopathy with gross cardiomegaly. Other prominent findings include hepatomegaly, macroglossia and markedly elevated creatine kinase (CK) levels. Life expectancy is, on average, less than a year, with only a quarter of patients surviving beyond one year.

\section{Juvenile and adult onset acid maltase deficiency}

The juvenile form of AMD, with onset from early childhood to adolescence, presents with progressive proximal muscle weakness in a limb girdle pattern, manifested as delayed milestones, or difficulty with walking, climbing stairs or getting up from sitting or lying. ${ }^{[31,33]}$ Spinal deformities may develop owing to truncal weakness. Calf hypertrophy and scapular winging has also been reported. Development of respiratory weakness may occur, with orthopnoea and dyspnoea on exertion. AMD starting in adult life is also associated with proximal weakness, sometimes with striking selective involvement. ${ }^{[34,35]}$ Respiratory weakness appears even more common in the adult form than the infantile form in the early stages, being the presenting symptom in about a third, and affecting all patients eventually. A late complication in juvenile and adult AMD is the development of cerebral aneurysm, especially basilar aneurysm, which may rupture. Unlike infantile AMD, cardiomyopathy is uncommon or absent, and the creatine kinase, though elevated, is not as high. The disease progresses more slowly, with severity correlating best with disease duration. 


\section{Differential diagnosis}

AMD should be suspected in the infant with a myopathy associated with organomegaly, especially cardiomegaly, weak muscles with firm consistency and ventilatory failure. It is in the differential diagnosis of the floppy baby with raised CK, and in infantile diseases with organomegaly. In young children and juveniles, AMD may be mistaken for muscular dystrophy, including Duchenne, Becker or a limb girdle muscular dystrophy, especially when there is associated calf hypertrophy, skeletal deformities and selective muscle involvement. In adults, AMD may be mistakenly diagnosed as polymyositis or limb girdle muscular dystrophy. AMD should always be in the differential diagnosis of myopathy associated with ventilatory failure, especially in juveniles and adults.

\section{Diagnostic tests}

As with MADD, the muscle biopsy often provides the first clear indication of the disease although in infantile Pompe's disease, evidence of cardiomegaly plus the characteristic Electrocardiogram (ECG), may also offer strong supporting evidence. The specific test required to confirm the disease is measurement of GAA activity. As a rapid diagnosis of AMD is important in infants with AMD for whom enzyme replacement therapy is planned, an international working group has recently published a consensus guide on laboratory diagnosis of Pompe's disease, which the reader may find helpful. ${ }^{[36]}$

\section{Muscle biopsy}

The typical finding of muscle biopsy in AMD is a vacuolar myopathy associated with glycogen storage, as demonstrated by Periodic Acid Schiff staining, and increased lysosomal activity, as suggested by increased acid phosphatase staining, which distinguishes it from other glycogen storage disorders. The histological picture in infantile AMD is highly characteristic, with marked widespread vacuolation and heavy glycogen accumulation. These changes are milder in the juvenile and adult forms of AMD, and may even be absent owing to 'sampling error'. This histological picture may possibly overlap with that of a disorder earlier reported as "lysosomal glycogen storage disease with normal acid maltase" and now identified as Danon's disease, although glycogen accumulation is not always seen in this rare autophagic vacuolar myopathy.

\section{Measurement of $\alpha$-glucosidase activity}

GAA activity may be assayed in lymphocytes, mixed leucocytes, fibroblasts or muscle tissue, as well as using dried blood spots, for diagnostic purposes. Although the most reliable measurement of residual GAA activity is in cultured fibroblasts, the ability to measure GAA activity in blood has simplified and expedited the test as no biopsy or tissue culture is required. The use of acarbose to eliminate interference by isoenzymes in blood has made this possible. ${ }^{[37]}$ Dried blood spots are especially convenient, and also suitable for shipping and for neonatal screening. ${ }^{\left[{ }^{38]}\right.}$ In infantile forms, the diagnosis is confidently verified by the complete absence of GAA activity. In juvenile and adult forms, GAA activity may range between absent to about $40 \%$ of normal. Where GAA activity is partially present, correlation with clinical and laboratory findings is necessary.

\section{Molecular gene diagnosis}

Molecular analysis of the GAA gene is usually not required for diagnosis if a reliable test to measure GAA activity is available. However, mutational analysis may be useful in mild cases in whom GAA activity may be near normal. GAA mutational analysis will be necessary if prenatal diagnosis is considered.

\section{Ancillary tests}

Several ancillary tests are appropriate in AMD, to support the diagnosis or characterize disease severity or complications. These may include ECG, chest X-ray and echocardiography, Electromyography (EMG) and nerve conduction studies, CK levels and pulmonary function tests. Myotonic discharges (without clinical myotonia) in association with features of an irritable myopathy are typically associated with all forms of AMD. While these EMG findings are useful when AMD is suspected, they may also give rise to misdiagnoses of inflammatory myopathy or myotonic dystrophy in the unaware examiner. The ECG in the infantile form shows typical features of shortened PR intervals associated with large QRS complexes.

\section{Treatment}

\section{Supportive therapy}

Despite the emergence of specific enzyme replacement therapy, general supportive therapy of AMD remains highly relevant, especially with regards to complications of feeding difficulty, general weakness, and respiratory failure and pulmonary infections. Respiratory support, in particular, with noninvasive techniques such as nocturnal Bipap, will significantly improve quality of life and extend survival in juveniles and adults with respiratory failure.

\section{Dietary therapy}

Dietary modifications tried in AMD, in an attempt to decrease glycogen deposition and increase utilization of alternate metabolic pathways, have included high protein intake with or without low caloric/ carbohydrate intake, and branched chain amino acid or L-alanine supplementation. In general, only single 
cases or small numbers of patients were studied, who were often older cases, in whom the disease progression is slower. No studies involved the infantile form and none were controlled. Some studies reported benefit ${ }^{[39-42]}$ while others reported little or no benefit. ${ }^{[4-47]}$ The exceptional study is that of Slonim et al., ${ }^{[8]}$ an uncontrolled prospective study of a highprotein, low-carbohydrate diet with exercise therapy in adult onset AMD cases. Comparing pre-therapy with post-therapy measurements, muscle function deterioration was reported to be significantly slowed by the therapy. However, eight of the original 34 cases could not adhere to the therapy regimen. It is, therefore, reasonable to conclude that dietary therapy is, at best, palliative, requires strict compliance and reported only in adult AMD cases.

\section{Enzyme replacement therapy}

Early trials of enzyme replacement using fungal or human derived enzyme were uniformly unsuccessful. ${ }^{[13,49]}$ The breakthrough came in stages, first with identification of the mannose6 -phosphate receptor on cell surfaces enabling efficient endocytosis of mannose-6-phosphate labeled enzyme ${ }^{[50]}$ and subsequently the development of recombinant DNA technologies to synthesize commercial quantities of human recombinant $\alpha$-glucosidase. ${ }^{[51]}$ Early pilot studies of recombinant GAA infusion in a few infantile patients were highly encouraging, ${ }^{[52,53]}$ followed by a Phase 1/II open label trial in 18 infantile AMD patients using a historical cohort as controls. ${ }^{[32,54]}$ The results were dramatic and convincing, with $100 \%$ survival compared to $2 \%$ survival in the historical cohort at 52 weeks. The need for invasive ventilation was reduced by $92 \%$ and cardiac and motor function was significantly improved. The beneficial effect of recombinant GAA was substantiated by an open label trial of two adolescents and an adult, reviewed at three years and five years. ${ }^{[5,56]}$ However, these studies also revealed that when treatment was initiated later, improvement was more limited and variable, especially with regards to ventilatory and motor function. This suggests that early diagnosis and treatment may be critical for better outcome. Serious or life-threatening reactions to recombinant GAA, specifically anaphylactic reactions, occurred in a few, warranting precautionary measures. However, the major factor prohibiting more general use of recombinant GAA is its high cost, especially in developing countries or where medical care is not subsidized, posing serious dilemmas for patients and their physicians. Nevertheless, the advent of enzyme replacement therapy has drastically changed the landscape for therapy of AMD. Firm confirmation of its promise to halt or reverse the disease process in AMD awaits longer term follow-up studies of all forms of AMD patients under treatment.

\section{References}

1. Amendt BA, Rhead WJ. The multiple acyl-coenzyme A dehydrogenation disorders, glutaric aciduria type II and ethylmalonic-adipic aciduria: Mitochondrial fatty acid oxidation, acyl-coenzyme A dehydrogenase, and electron transfer flavoprotein activities in fibroblasts. J Clin Invest 1986;78:205-13.

2. Christensen E, Kolvraa S, Gregersen N. Glutaric aciduria type II: Evidence for a defect related to the electron transfer flavoprotein or its dehydrogenase. Pediatr Res 1984;18:663-7.

3. Frerman FE, Goodman SI. Defects of electron transfer flavoprotein and electron transfer flavoprotein-ubiquinone oxidoreductase: Glutaric aciduria type II. In: Scriver CR, Baudet AL, Sly WS, Valle D, editors. The metabolic and molecular basis of inherited disease. 8 ed. New York: McGraw-Hill; 2001. p. 2357-65.

4. Olsen RK, Olpin SE, Andresen BS, Miedzybrodzka ZH, Pourfarzam M, Merinero B, \& al. ETF-DH mutations as a major cause of riboflavinresponsive multiple acyl-CoA dehydrogenation deficiency. Brain 2007;130:2045-54

5. Gregersen N. Riboflavin-responsive defects of beta-oxidation. J Inherit Metab Dis 1985;8:65-9.

6. Colombo I, Finocchiaro G, Garavaglia B, Garbuglio N, Yamaguchi S, Frerman FE, \& al. Mutations and polymorphisms of the gene encoding the beta-subunit of the electron transfer flavoprotein in three patients with glutaric acidemia type II. Hum Mol Genet 1994;3:429-35.

7. Schiff M, Froissart R, Olsen RK, Acquaviva C, Vianey-Saban C. Electron transfer flavoprotein deficiency: Functional and molecular aspects. Mol Genet Metab 2006;88:153-8.

8. Loehr JP, Goodman SI, Frerman FE. Glutaric acidemia type II: Heterogeneity of clinical and biochemical phenotypes. Pediatr Res $1990 ; 27: 311-5$.

9. Mantagos S, Genel M, Tanaka K. Ethylmalonic-adipic aciduria: In vivo and in vitro studies indicating deficiency of activities of multiple acyl-CoA dehydrogenases. J Clin Invest 1979;64:1580-9.

10. al-Essa MA, Rashed MS, Bakheet SM, Patay ZJ, Ozand PT. Glutaric aciduria type II: Observations in seven patients with neonatal- and lateonset disease. J Perinatol 2000;20:120-8.

11. Yamaguchi S, Orii T, Suzuki Y, Maeda K, Oshima M, Hashimoto T. Newly identified forms of electron transfer flavoprotein deficiency in two patients with glutaric aciduria type II. Pediatr Res 1991;29:60-3.

12. Olsen RK, Andresen BS, Christensen E, Bross P, Skovby F, Gregersen N. Clear relationship between ETF/ETF-DH genotype and phenotype in patients with multiple acyl-CoA dehydrogenation deficiency. Hum Mutat 2003;22:12-23.

13. de VM, Scholte HR, Schutgens RB, Bolhuis PA, Luyt-Houwen IE, Vaandrager-Verduin MH, \& al. Riboflavin-responsive lipid-storage myopathy and glutaric aciduria type II of early adult onset. Neurology 1986;36:367-72.

14. Gempel K, Topaloglu H, Talim B, Schneiderat P, Schoser BG, Hans $\mathrm{VH}, \mathrm{A}$ al. The myopathic form of coenzyme Q10 deficiency is caused by mutations in the electron-transferring-flavoprotein dehydrogenase (ETF-DH) gene. Brain 2007;130:2037-44.

15. Beresford MW, Pourfarzam M, Turnbull DM, Davidson JE. So doctor, what exactly is wrong with my muscles? Glutaric aciduria type II presenting in a teenager. Neuromuscul Disord 2006;16:269-73.

16. Przyrembel H, Wendel U, Becker K, Bremer HJ, Bruinvis L, Ketting D, \& al. Glutaric aciduria type II: Report on a previously undescribed metabolic disorder. Clin Chim Acta 1976;66:227-39.

17. Green A, Marshall TG, Bennett MJ, Gray RG, Pollitt RJ. Riboflavinresponsive ethylmalonic-adipic aciduria. J Inherit Metab Dis 1985;8: 67-70.

18. Abdenur JE, Chamoles NA, Schenone AB, Jorge L, Guinle A, Bernard C, \& al. Multiple acyl-CoA-dehydrogenase deficiency (MADD): Use of acylcarnitines and fatty acids to monitor the response to dietary treatment. Pediatr Res 2001;50:61-6.

19. Gregersen N, Christensen MF, Christensen E, Kolvraa S. Riboflavin responsive multiple acyl-CoA dehydrogenation deficiency: Assessment of 
3 vears of riboflavin treatment. Acta Paediatr Scand 1986;75:676-81.

20. Peluchetti D, Antozzi C, Roi S, DiDonato S, Cornelio F. Riboflavin responsive multiple acyl-CoA dehydrogenase deficiency: Functional evaluation of recovery after high dose vitamin supplementation. J Neurol Sci 1991;105:93-8.

21. Green A, Preece MA, de SC, Pollitt RJ. Possible deleterious effect of L-carnitine supplementation in a patient with mild multiple acyl-CoA dehydrogenation deficiency (ethylmalonic-adipic aciduria). J Inherit Metab Dis 1991;14:691-7.

22. Hirschhorn R, Reuser AJJ. Glycogen storage disease type II: Acid alpha-glucosidase (acid maltase)deficiency. In: Scriver CR, Baudet AL, Sly WS, Valle D, editors. The Metabolic and Molecular Basis of Inherited Disease. 8 ed. New York: McGraw-Hill; 2001. p. 3389-420.

23. Raben N, Plotz P, Byrne BJ. Acid alpha-glucosidase deficiency (glycogenosis type II, Pompe disease). Curr Mol Med 2002;2:145-66.

24. Hers HG. Alpha-Glucosidase deficiency in generalized glycogenstorage disease (Pompe's disease). Biochem J 1963;86:11-6.

25. Raben N, Nichols RC, Boerkoel C, Plotz P. Genetic defects in patients with glycogenosis type II (acid maltase deficiency). Muscle Nerve 1995;3:S70-4

26. D'Ancona GG, Wurm J, Croce CM. Geneties of type II glyeogenosis: Assignment of the human gene for acid alpha-glucosidase to chromosome 17. Proc Natl Acad Sci U S A 1979;76:4526-9.

27. Huie ML, Chen AS, Tsujino S, Shanske S, DiMauro S, Engel AG, \& al. Aberrant splicing in adult onset glycogen storage disease type II (GSDII): Molecular identification of an IVS1 (-13T-->G) mutation in a majority of patients and a novel IVS10 (+1GT-->CT) mutation. Hum Mol Genet 1994:3:2231-6

28. Shieh JJ, Lin CY. Frequent mutation in Chinese patients with infantile type of GSD II in Taiwan: Evidence for a founder effect. Hum Mutat 1998; 11:306-12.

29. Ausems MG, Verbiest J, Hermans MP, Kroos MA, Beemer FA, Wokke JH, e al. Frequency of glycogen storage disease type II in The Netherlands: Implications for diagnosis and genetic counselling. Eur J Hum Genet 1999;7:713-6.

30. Martiniuk F, Chen A, Mack A, Arvanitopoulos E, Chen Y, Rom WN, \& al. Carrier frequency for glyeogen storage disease type II in New York and estimates of affected individuals born with the disease. Am J Med Genet 1998;79:69-72.

31. Winkel LP, Hagemans ML, Van Doorn PA, Loonen MC, Hop WJ, Reuser AJ, \&al. The natural course of non-classic Pompe's disease: A review of 225 published cases. J Neurol 2005;252:875-84.

32. Kishnani PS, Hwu WL, Mandel H, Nicolino M, Yong F, Corzo D. A retrospective, multinational, multicenter study on the natural history of infantile-onset Pompe disease. J Pediatr 2006;148:671-6.

33. Zellweger H, Brown BI, McCormick WF, Tu JB. A mild form of muscular glyeogenosis in two brothers with alpha-1, 4-glucosidase deficiency. Ann Paediatr 1965;205:413-37.

34. Hudgson P, Gardner-Medwin D, Worsfold M, Pennington RJ, Walton JN. Adult myopathy from glyeogen storage disease due to acid maltase deficiency. Brain 1968;91:435-62.

35. Hagemans ML, Winkel LP, Van Doorn PA, Hop WJ, Loonen MC, Reuser AJ, đal. Clinical manifestation and natural course of late-onset Pompe's disease in 54 Dutch patients. Brain 2005;128:671-7.

36. Winchester B, Bali D, Bodamer OA, Caillaud C, Christensen E, Cooper A, \&al. Methods for a prompt and reliable laboratory diagnosis of Pompe disease: Report from an international consensus meeting. Mol Genet Metab 2008;93:275-81

37. Okumiya T, Keulemans JL, Kroos MA, Van der Beek NM, Boer MA, Takeuchi H, e al. A new diagnostic assay for glycogen storage disease type II in mixed leukocytes. Mol Genet Metab 2006;88:22-8.

38. Umapathysivam K, Hopwood JJ, Meikle PJ. Determination of acid alpha-glucosidase activity in blood spots as a diagnostic test for Pompe disease. Clin Chem 2001;47:1378-83.
39. Demey HE, Van Meerbeeck JP, Vandewoude MF, Prove AM, Martin JJ, Bossaert LL. Respiratory insufficiency in acid maltase deficiency: The effect of high protein diet. J Parenter Enteral Nutr 1989;13:321-3.

40. Mobarhan S, Pintozzi RL, Damle P, Friedman H. Treatment of acid maltase deficiency with a diet high in branched-chain amino acids. J Parenter Enteral Nutr 1990;14:210-2.

41. Margolis ML, Hill AR. Acid maltase deficiency in an adult. Evidence for improvement in respiratory function with high-protein dietary therapy Am Rev Respir Dis 1986;134:328-31.

42. Slonim AE, Coleman RA, McElligot MA, Najjjar J, Hirschhorn K, Labadie GU, \& al. Improvement of muscle function in acid maltase deficiency by high-protein therapy. Neurology 1983;33:34-8.

43. Ravaglia S, Pichiecchio A, Rossi M, Filippi PD, Minelli A, Moglia A, \& al. Dietary treatment in adult-onset type II glycogenosis. J Inherit Metab Dis 2006;29:590

44. Mundy HR, Williams JE, Cousins AJ, Lee PJ. The effect of L-alanine therapy in a patient with adult onset glycogen storage disease type II. $J$ Inherit Metab Dis 2006;29:226-9.

45. Padberg GW, Wintzen AR, Giesberts MA, Sterk PJ, Molenaar AJ, Hermans J. Effects of a high-protein diet in acid maltase deficiency. J Neurol Sci 1989;90:111-7.

46. Ferrer X, Coquet M, Saintarailles J, Ellie E, Deleplanque B, Desnuelle C, \&al. [Myopathy in adults caused by acid maltase deficiency: A trial of treatment with high protein diet]. Rev Med Interne 1992;13:149-52.

47. Bodamer OA, Leonard JV, Halliday D. Dietary treatment in late-onset acid maltase deficiency. Eur J Pediatr 1997;156:S39-42.

48. Slonim AE, Bulone L, Goldberg T, Minikes J, Slonim E, Galanko J, đal. Modification of the natural history of adult-onset acid maltase deficiency by nutrition and exercise therapy. Muscle Nerve 2007;35:70-7.

49. Lauer RM, Mascarinas T, Racela AS, Diehl AM, Brown BI. Administration of a mixture of fungal glucosidases to a patient with type II glycogenosis (Pompe's disease). Pediatrics 1968;42:672-6.

50. Reuser AJ, Kroos MA, Ponne NJ, Wolterman RA, Loonen MC, Busch HF, \& al. Uptake and stability of human and bovine acid alpha-glucosidase in cultured fibroblasts and skeletal muscle cells from glycogenosis type II patients. Exp Cell Res 1984;155:178-89.

51. Van Hove JL, Yang HW, Wu JY, Brady RO, Chen YT. High-level production of recombinant human lysosomal acid alpha-glucosidase in Chinese hamster ovary cells which targets to heart muscle and corrects glycogen accumulation in fibroblasts from patients with Pompe disease. Proc Natl Acad Sci USA 1996;93:65-70.

52. Van den Hout JM, Kamphoven JH, Winkel LP, Arts WF, De Klerk JB, Loonen MC, \& al. Long-term intravenous treatment of Pompe disease with recombinant human alpha-glucosidase from milk. Pediatrics 2004;113:448-57

53. Kishnani PS, Nicolino M, Voit T, Rogers RC, Tsai AC, Waterson J, \& al. Chinese hamster ovary cell-derived recombinant human acid alphaglucosidase in infantile-onset Pompe disease. J Pediatr 2006;149:89-97.

54. Kishnani PS, Corzo D, Nicolino M, Byrne B, Mandel H, Hwu WL, eal. Recombinant human acid [alpha]-glucosidase: Major clinical benefits in infantile-onset Pompe disease. Neurology 2007;68:99-109.

55. Winkel LP, Van den Hout JM, Kamphoven JH, Disseldorp JA, Remmerswaal M, Arts WF, \& al. Enzyme replacement therapy in lateonset Pompe's disease: A three-year follow-up. Ann Neurol 2004;55: 495-502.

56. van Capelle CI, Winkel LP, Hagemans ML, Shapira SK, Arts WF, Van Doorn PA, đal. Eight years experience with enzyme replacement therapy in two children and one adult with Pompe disease. Neuromuscul Disord $2008 ; 18: 447-52$

Accepted on 28-08-2008

Source of Support: Nil, Conflict of Interest: None declared. 